\title{
periferio
}

\section{PÓS-COLONIALISMO, EDUCAÇÃO E CONSCIÊNCIA CRÍTICA LATINO-AMERICANA EM “ARIEL”, DE RODÓ}

\author{
Raimundo Nonato de Pádua Câncio ${ }^{1}$ \\ Universidade Federal do Pará - UFPA \\ Andreson Carlos Elias Barbosa ${ }^{2}$ \\ Universidade Federal do Pará - UFPA
}

\section{Resumo}

O objetivo deste artigo é analisar o pensamento sobre educação do escritor uruguaio José Enrique Rodó, que fez parte do movimento literário conhecido como “Geração Hispano-Americana de 98", a partir de sua obra Ariel, publicada em 1900. Neste ensaio, é possível observar como este intelectual idealizou a constituição de uma identidade latino-americana em pleno modernismo hispano-americano. Trata-se de um estudo de caráter bibliográfico que posiciona o literato dentre os intelectuais mais importantes de seu país, a partir das reflexões levantadas de combate à influência estadunidense, apresentada ostensivamente no ano de 1898. Em Ariel, Rodó demonstra a importância da educação na definição da cultura e da política de um povo, e delineia uma cultura latino-americana valorosa, altruísta, oposta ao utilitarismo frio, egoísta e estadunidense.

Palavras chave: Rodó; educação; pós-colonialismo

\footnotetext{
1 Professor de Língua Portuguesa da SEDUC-PA e doutorando em Educação no Programa de Pós-graduação em Educação da Universidade Federal do Pará, na linha de pesquisa "Educação, Cultura e Sociedade". Está vinculado ao Grupo de Pesquisa “José Veríssimo e o Pensamento Educacional Latino-americano (ICED/UFPA). E-mail: nonatocancio@hotmail.com

${ }^{2}$ Analista Judiciário do Tribunal de Justiça do Estado do Pará e doutorando em Educação no Programa de Pós-graduação em Educação da Universidade Federal do Pará, na linha de pesquisa "Educação, Cultura e Sociedade". Está vinculado ao Grupo de Pesquisa "José Veríssimo e o Pensamento Educacional Latino-americano (ICED/UFPA). E-mail: aceb@oi.com.br
} 


\section{periferio}

\section{POST-COLONIALISM, EDUCATION AND LATIN AMERICAN CRITICAL CONSCIOUSNESS IN "ARIEL", OF RODÓ}

\section{Abstract}

The purpose of this article is to analyze the thinking about education of Uruguayan writer José Enrique Rodó, who was part of the literary movement known as "Hispano-American Generation of 98", from his work Ariel, published in 1900. In this essay, It is possible to observe how this intellectual idealized the constitution of a Latin American identity in full Hispanic-American modernism. It is a study of a bibliographic character that positions the writer among the most important intellectuals of his country, based on the reflections raised against American influence, presented ostensibly in the year 1898. In Ariel, Rodó demonstrates the importance of education in definition of the culture and politics of a people, and delineates a latin american culture that is valiant, altruistic, opposed to cold, selfish, and American utilitarianism.

Keywords: Rodó; education; postcolonialism 


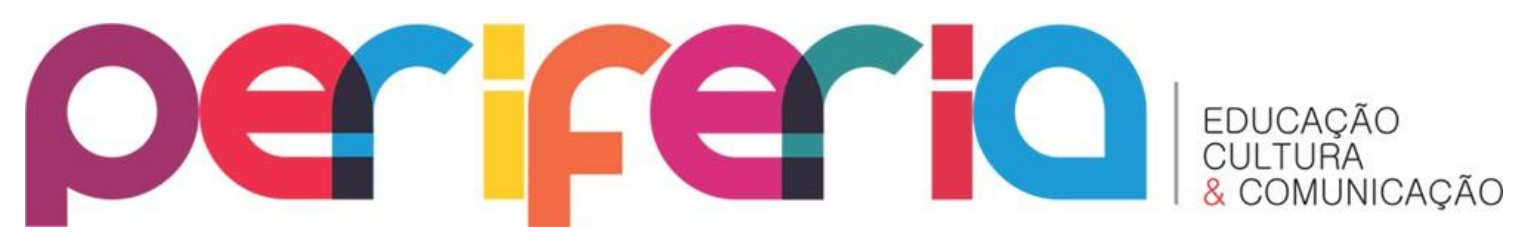

INTRODUÇÃO

A teoria pós-colonial se debruça, fundamentalmente, no modo como se baseiam as explicações e a compreensão do mundo na crítica às relações desiguais entre o Norte/centro e o Sul/periferia. Revela-se um campo heterogêneo e de difícil delimitação, devido às várias correntes e as diversas vertentes de seus intelectuais ${ }^{3}$, na sua maioria em situação diaspórica, já que emergem de países ditos periféricos ou semiperiféricos do sistema mundial. Um ponto comum entre esses intelectuais é a formação de uma consciência anticolonialista, que subverte o que denominamos de ideias com base na matriz da relação colonial e no modo como desenvolvem essa crítica, a partir da incorporação do ponto de vista dos colonizados.

O ensaio de ficção Ariel (1900), do uruguaio José Enrique Rodó, publicado em 1900 e produzido pelo autor em seu país de origem, tornou-se referência entre leitores e críticos acerca dos problemas político-culturais vivenciados na América Latina, com destaque para um acontecimento ocorrido no ano de 1898: a Guerra Hispano-Americana ${ }^{4}$. Os fundamentos dessas questões e suas implicações para o pensamento latino-americano podem ser identificados quando realizamos um estudo de Ariel, verdadeiro manifesto das teorias identitárias idealistas expressas pelos intelectuais da "Geração de 98". Contudo, este artigo tem como objetivo identificar e analisar, nesse contexto, o pensamento de Rodó sobre educação, considerando as características que o mesmo julga positivas na cultura

\footnotetext{
${ }^{3}$ Os intelectuais expoentes desse pensamento são teóricos anticoloniais como, entre outros, Frantz Fanon, Albert Memmi, Aimé Césaire, Édouard Glissant ou Amílcar Cabral, os quais, a partir da perspectiva dos oprimidos, desenvolveram uma consciência anticolonialista, com um modelo de discurso crítico dissidente, enquanto discurso da diferença, no seio da relação póscolonial.

${ }^{4}$ A Guerra Hispano-Americana marcou o ano de 1898 e resultou na independência da itha de Cuba. Em sua luta armada para alcançar a independência da Espanha, os cubanos tiveram auxílio militar dos Estados Unidos, que gradativamente firmavam seu status de potência mundial (TURATTI, 2012, p. 218).
} 


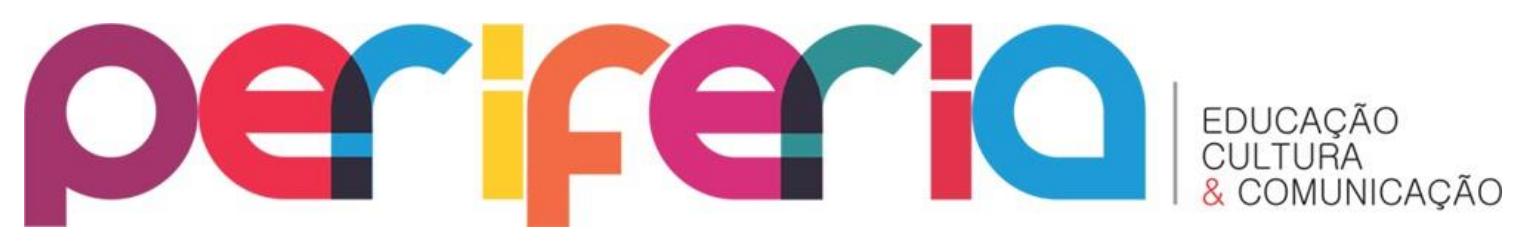

europeia, quando propõe esses valores como referência para a constituição identitária da América Latina.

O texto está organizado em três seções. Na primeira, damos ênfase aos aspectos biográficos do escritor uruguaio, assim como estabelecemos o seu lugar no debate intelectual na modernização e na internacionalização da economia. Na segunda seção, abordamos a crítica pós-colonial, as relações de poder e suas repercussões na literatura latino-americana, com destaque para o pensamento crítico de Rodó. Por fim, na terceira seção, discutimos a educação latino-americana espiritualizada como paradigma crítico e de combate, na visão do literato, aos fundamentos materialistas estadunidenses.

Trata-se, portanto, de um estudo de caráter bibliográfico que posiciona o escritor uruguaio como um dos intelectuais mais importantes de seu país, naquele contexto histórico, dadas as reflexões levantadas em Ariel que combatem e recusam a influência utilitarista estadunidense. A abordagem teórico-metodológica do estudo situa-se na intersecção de horizontes teóricos interdisciplinares, já que abarca a questão do pós-colonialismo e educação, a história dos intelectuais e os estudos literários e culturais.

\section{JOSÉ ENRIQUE RODÓ: A PRODUÇÃO LITERÁRIA E A CONSTRUÇÃO DO SENTIMENTO IDENTITÁRIO NO URUGUAI DO INÍCIO DO SÉCULO XX}

José Enrique Camilo Rodó Piñeyro é considerado um dos mais expressivos escritores uruguaios na passagem do século XIX para o século $X X$. Nasceu em Montevidéu, no dia 15 de julho de 1872, e morreu em Palermo, no dia $1^{\circ}$ de maio de 1917. Passou a maior parte de sua vida em Montevidéu, dedicando-se à leitura, à escrita, ao ensino e à atividade política. Em 1895, ajudou a fundar a Revista Nacional de Literatura y Ciencias Sociales. Nesta revista publicou textos que expressavam sua preocupação americanista, como em El que vendrá (1897) e em La vida nueva (1897), nos quais aborda as razões para a crise do ocidente. 


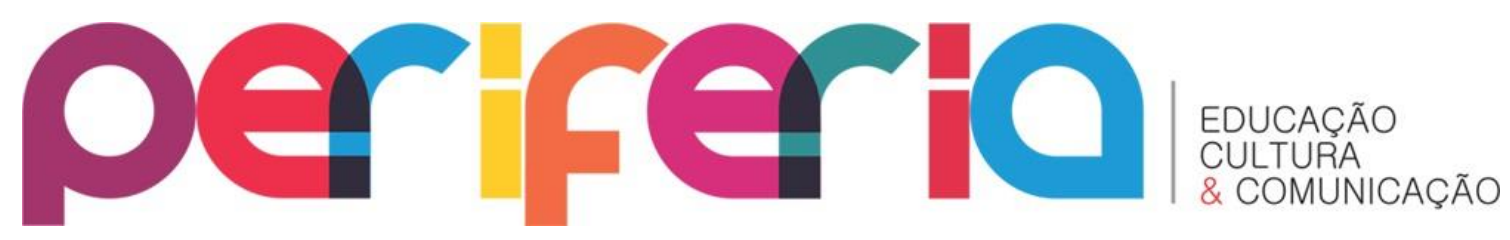

A partir de 1898, tornou-se professor de Literatura na Universidade Nacional (Universidade da República), em Montevidéu; atuou como diretor da Biblioteca Nacional do Uruguai; e foi, por duas vezes (1902 e 1908), membro do Parlamento Europeu pelo Partido Colorado, ao qual esteve filiado. Como parlamentar, sua atuação ficou marcada pela defesa da cultura e da educação, pois lutou por questões como o direito à bolsa de estudo, financiamento estudantil e edições de importantes obras. Em 1916, mudou-se para a Europa e atuou como correspondente de Caras e Máscaras. Considerado um dos maiores ensaístas do Modernismo hispano-americano, foi o autor de Ariel (1900), obra que propôs o idealismo espiritual como recurso de defesa contra a crescente dominação hispano-americana, liderada pelos Estados Unidos.

O filósofo, jornalista e ensaísta uruguaio foi defensor atento de uma cultura hispano-americana idealista, em oposição ao materialismo desenfreado representado pela política expansionista norte-americana, sob a pretensão de se afirmarem como eixo do capital no mercado mundial. Ariel talvez seja o texto mais influente de todo aparato intelectual latinoamericano, dado a ênfase ao seu modelo de educação pela cultura, que se contrapunha ao utilitarismo dos Estados Unidos.

Os escritos de Rodó afirmavam a necessidade de se construir um pensamento político e social genuinamente latino-americano, posicionando-se contra a ingenuidade dos aristocratas autóctones em tentar reproduzir acriticamente o modelo societário norte-americano. Ao longo de sua vida e obra, o literato defendeu os princípios idealistas, por meio da participação no movimento literário modernista e também pelo seu engajamento partidário. Além de Ariel, o escritor ainda escreveu outras obras, entre elas, Motivos de Proteo (1908) e El mirador de Próspero (1913).

A realidade da América Latina foi preocupação constante de Rodó, principalmente pelo fato de que havia admiração excessiva dos intelectuais e políticos latino-americanos pelos Estados Unidos. Para ele, isso fazia com que a identidade sul-americana se tornasse ameaçada, uma vez que tal fascínio 


\section{periferio}

era desencadeado pela política imperialista, iniciada nessa mesma época, o que colocava em perigo a independência e a soberania de determinadas repúblicas hispano-americanas.

A atividade intelectual e a postura como escritor, além do forte posicionamento em seus discursos, fez com que ele se tornasse, de certa forma, a representação de intelectual de seu tempo. Foi a construção de um sentimento identitário a principal marca do escritor, fundamentado e articulado a um processo histórico de longa duração, efetuando-se na virada do século, e difundindo-se no momento em que os Estados Unidos se voltam a manchar os preceitos supostamente solidários do pan-americanismo monroísta, o que se deu com uma série de práticas de cunho imperialista.

Desde 1828, com a sua independência, o Uruguai vivenciou um longo período de instabilidade política. Houve a sucessão de vários golpes de Estado promovidos por caudilhos ${ }^{5}$ e militares, e longas guerras, como a Guerra Grande (1839-1851). Nesse ínterim, também acentuaram-se as intervenções europeias, as guerras civis, prolongando-se até a segunda metade do século XIX. Após vivenciado um período de certa estabilidade administrativa e de liberdade política, o que se dá nos anos de 1890 a 1897, o Uruguai foi novamente abalado por um golpe, e uma nova guerra civil, que somente terminaria em 1904, com a morte do caudilho Aparício Saravia6.

A guerra civil de 1904 tocou profundamente a consciência de Rodó, o que pode ser evidenciado em suas cartas e em outros testemunhos desta sua experiência imediata, que acabou por comprometer muitas de seus melhores ideais. Em carta ao amigo Juan Francisco Piquet" ${ }^{7}$, assim ele descreve: "Por

\footnotetext{
${ }^{5}$ A corrente do caudilhismo teve grande expressividade na América Latina, principalmente nos países que foram colonizados pela Espanha. Historicamente, eles foram se formando ao longo da independência das nações latino-americanas e de suas colônias. Eram senhores de terra que queriam fazer prevalecer seus direitos acima dos outros de qualquer maneira.

${ }^{6}$ Foi um político, militar e caudilho do Partido Blanco do Uruguai. Neste país, atuou militar e, politicamente, pelo Partido Blanco nas disputas internas, transformando-se no líder máximo de seu partido.

7 Piquet, nascido em 1870, um ano antes de Rodó, era um amigo da primeira hora. Foi também um dos primeiros a escrever a biografia de Rodó, onde retrata o homem e o escritor.
} 


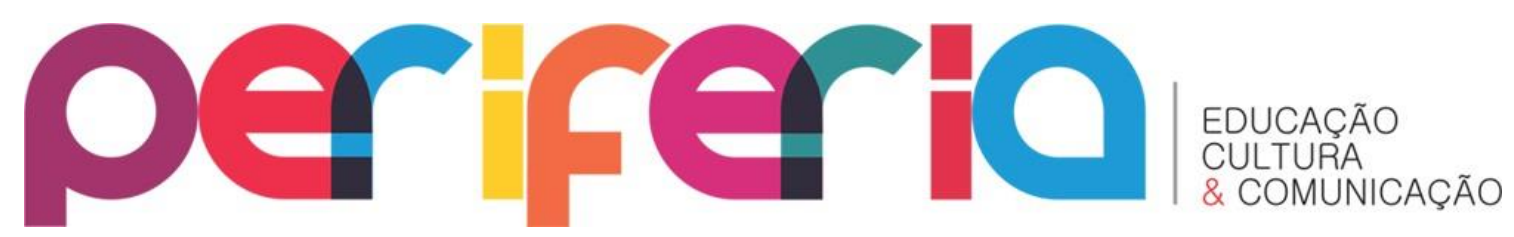

aqui tudo é o mesmo: a guerra e a miséria, os senhores da guerra e os fanáticos, rios de sangue e furacões de ódio. Em tudo isso, a vida febril; e de outra forma, a morte e o silêncio." (RODÓ, 1967, p. 34, Tradução nossa).

O Uruguai nos últimos trinta anos do século XIX também iniciou um acelerado processo de modernização (RAMA, 1985, p. 76). Naquele momento, este país enfrentava, no plano subjetivo, o conhecido conflito entre a tradição e a modernidade. Em um período que o mundo urbano ganhava contornos mais nítidos e complexos, tornou-se lugar comum o confronto entre a mentalidade criolla, de raízes essencialmente agrárias, e o que poderíamos chamar de "consciência cosmopolita emergente" (MITRE, 2003, p. 110).

Ao problematizar o cenário da modernidade, Quijano (2009) observa que a América constitui-se como primeiro espaço/tempo de um padrão de poder de vocação mundial e, desse modo, apresenta-se como a primeira identidade da modernidade. Assim, tal padrão de poder passa a ser elaborado e formalizado sob um modo de produzir conhecimento que dava conta das necessidades cognitivas do capitalismo.

Este modelo de conhecimento foi, pelo seu caráter e pela sua origem, imposto e admitido no mundo capitalista como a única racionalidade válida e como emblema da modernidade (QUIJANO, 2009 p. 74). A revolta intelectual contra essa perspectiva e esse modo de produzir conhecimento nunca esteve ausente, principalmente na América Latina.

Ao refletir sobre os argumentos utilizados para a avançada modernização comandada pelos Estados Unidos, José Enrique Rodó, em Ariel, declarou-se admirador da sociedade norte-americana, embora enfatizasse que isso não deveria acarretar na reprodução acrítica do modelo civilizatório por eles apresentado. Seu apelo à juventude da América Latina é uma convocação que reflete a urgência do estabelecimento de um contraponto frente à influência, aparentemente natural, exercida pelos Estados Unidos no continente. "Natural" porque o autor reconhece aquele país como a grande potência econômica e política da região, grandeza que por consequência 


\section{periferio}

inspira as demais nações, convertendo-as em fiéis admiradoras (RODÓ, 1991, p. 69-77).

Ariel é uma obra que chama atenção pela riqueza de detalhes, pois o autor utiliza-se de personagens presentes em obras clássicas da literatura ocidental, como Próspero, Calibã e Ariel, da peça A Tempestade, de William Shakespeare. No final da obra, é dado destaque ao jovem Enjolras ${ }^{8}$, personagem de Os Miseráveis, de Victor Hugo. Enjolras é um revolucionário radical que lidera a insurreição de 1832 na França, mas que acaba fuzilado por um esquadrão do governo francês. Assim, Rodó faz referências à diversas obras e a personagens clássicos, em situações de conflito, na criação de um novo discurso que tem, por sua vez, o objetivo de fazer refletir sobre os conflitos vividos no território latino-americano.

Fica evidente, portanto, que sua matriz teórica é de vertente europeia, o que pode ser comprovado nas citações aos pensamentos de Renan, Guyau, Comte, Carlyle, Spencer, entre outros. Suas recorrências a estes pensadores se dão, na maioria das vezes, em razão de ele considerar os espíritos de muitos deles como exemplo do que há de belo e bom, pressupostos imprescindíveis para que passe a idealizar uma juventude americana com status supremo.

Do ponto de vista de sua estrutura, Ariel está dividida em seis partes, além de um prólogo e um epílogo que dão conta das informações introdutórias. Na primeira parte, Rodó trata da necessidade de uma juventude ativa, voltada à realização de metas e ideais. Na segunda parte, ele passa a introduzir a indesejável disseminação do utilitarismo empobrecedor e mutilador do espírito, uma vez que isso estabelece a tirania. Aponta a necessidade de se reservar uma parte da alma para as preocupações ideias,

\footnotetext{
${ }^{8}$ Em Os Miseráveis, Enjolras é um jovem charmoso e de beleza angelical, apaixonadamente dedicado à democracia, à igualdade e à justiça. É um homem de princípios que acredita em uma causa, a criação de uma república, libertando os pobres, sem qualquer dúvida. Mas este é executado pela Guarda Nacional após a queda da barricada.
} 


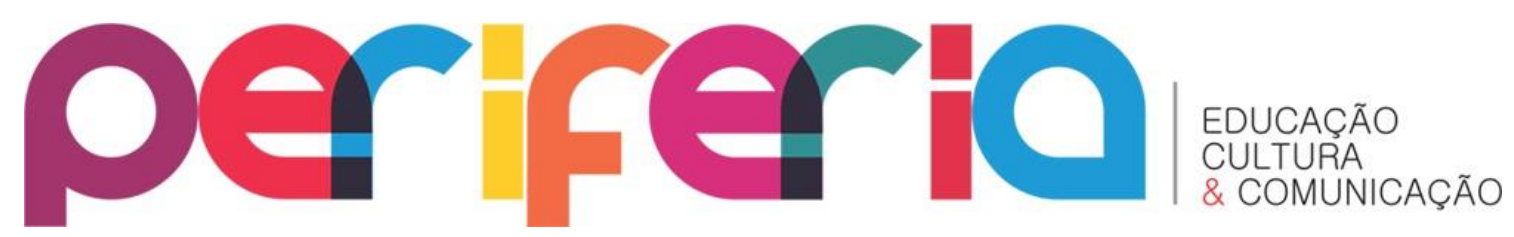

pois, para ele, deve-se "desenvolver no possível não apenas um aspecto, mas a plenitude de vosso ser" (Ibid., p. 27).

$\mathrm{Na}$ terceira parte, o literato chama atenção para a valorização do sentimento do belo para a educação do espírito, o que está representado quando Próspero diz: "Parece-me indubitável que quem aprendeu a distinguir entre o vulgar e o delicado, o feio e o belo, já tem meio caminho andado para distinguir entre o mal e o bem" (Ibid., p. 41). Na quarta parte, o escritor apresenta as prováveis causas e intensifica a crítica ao utilitarismo. Mas somente na quinta e na sexta parte e nos segmentos finais da obra é que o autor abordará a questão da ciência e sua aplicação útil, da intelectualidade decadente e da democracia mal entendida, o que será exposto e questionado por Próspero.

Portanto, Caliban, Ariel e Próspero, são personagens utilizados por Rodó para expressar seus temores e suas soluções, e representam em Ariel a personificações das forças sociais principais que se confrontavam na época: o Velho e o Novo Mundo. 0 uruguaio, inspirado pela crítica à cultura de massas e influenciado por seu "mestre" Renan reinterpretou os personagens de Shakespeare na situação da América Latina na virada do século. Nesta obra, Próspero continua sendo a Europa (mais velha e sábia) e Caliban é a força destruidora do mal, representada pelos Estados Unidos. Assim, "el problema fundamental considerado por Rodó no era específicamente hispanoamericano: era, es, el problema de la relación entre la cultura y la democracia" (MARICHAL, 1978, p. 80).

O cenário político-filosófico nacional e internacional é perceptível em Ariel e demonstra a racionalidade vivenciada com o advento da modernidade. Várias transformações sociais, como a mudança na urbanização, nos padrões demográficos e nos modos de produção da vida ocidental na virada do século causaram desconforto aos intelectuais da época, o que para eles era concebido como um estado de crise. Com isso, cresce também uma cultura de contrassenso, de crítica, que se sustenta como oposição a esse novo modo de vida, considerada para muitos como uma vida alienada. 


\section{periferio}

\section{PÓS-COLONIALISMO, PODER E LITERATURA LATINO-AMERICANA}

A crítica pós-colonial consiste em uma abordagem que visa compreender o imperialismo e suas influências, sendo alvos de sua preocupação as práticas de dominação e colonização. Portanto, tal perspectiva tem como papel central perturbar a estabilidade dos significados, mexendo e remexendo nos substratos dos textos (ANDO; BONICCI, 2005, p. 20). Na perspectiva da análise literária, a abordagem crítica pós-colonial dá atenção especial à preservação e documentação da literatura "produzida pelos povos degradados como 'selvagens', 'primitivos' e 'incultos' pelo imperialismo; a recuperação das fontes alternativas da força cultural de povos colonizados; o reconhecimento das distorções produzidas pelo imperialismo e ainda mantidas pelo sistema capitalista atual” (BONNICI, 1998, p. 10).

Além disso, Bonnici (2000) observa que nesta direção se discute também, além da função da literatura ocidental na perspectiva imperialista, o papel da literatura nacional para o povo colonizado. Trata-se de textos, como o ensaio Ariel, que, na sua maioria, descrevem uma fase revolucionária e nacionalista, em que o nativo realmente toma contato com as realidades da opressão colonial, e luta em prol de uma democratização da conscientização, bem como da expressão cultural e literária (ANDO; BONICCI, 2005, p. 22).

A teoria pós-colonial, portanto, ao dar ênfase na fase revolucionária e nacionalista, analisa não apenas as relações entre o colonizador e o colonizado, mas também a maneira como a construção do primeiro acontece por meio da fabricação do segundo, em condições de hierarquização (BONICCI, 2005, p. 151). Na história da literatura latino-americana9 há produção de várias obras em que se evidencia a resistência ao colonizador, à colonização, ao imperialismo e à globalização.

\footnotetext{
${ }^{9}$ Entre os intelectuais que apresentam significativas contribuições para o processo de resgate do paradigma identitário latino-americano, destacamos José Martí; Eduardo Prado; José Rodó; Manoel Bomfim; José Carlos Mariátegui; e Victor Raúl Haya de la Torre.
} 


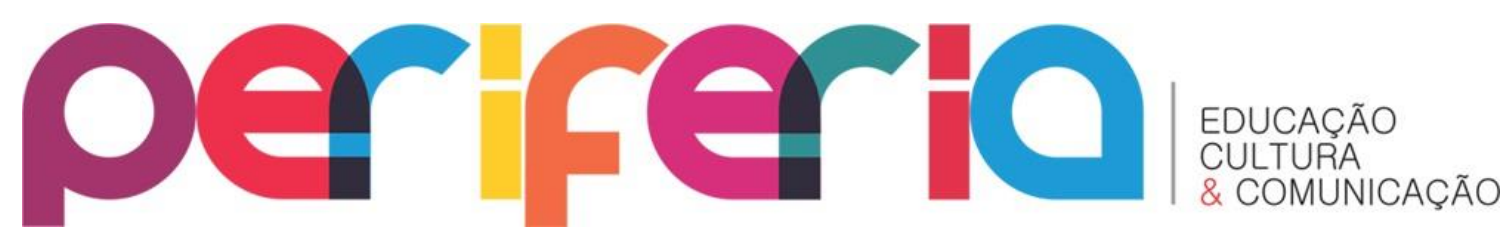

Há também uma geração de intelectuais responsáveis por reforçar a identidade comum latino-americana. Com análise alicerçada em preceitos materialistas, José Carlos Mariátegui, fundador do Partido Comunista Peruano, responsabilizava os Estados Unidos e a Inglaterra, ambos considerados países imperialistas, pelos danos sociais e econômicos provocados ao Peru e, por consequência, à América Latina (MARIÁTEGUI, 2008, p. 55).

José Martí, no ensaio Nuestra América (1891), dá maior densidade, pelo seu poder de argumentação, defende o processo de construção identitária latino-americana. Martí inicia seu texto com uma mensagem pela qual clama a todos de nossa América para se conhecerem e se unirem, pois, para ele, "Os povos que não se conhecem devem ter pressa em se conhecer, como aqueles que vão lutar juntos". (MARTí, 1983, p. 194).

A perspectiva eurocêntrica de conhecimento "imperava” nas Américas por meio da colonialidade do poder. A filosofia positivista de inspiração comteana foi dominante, articulada pelas minorias hegemônicas da sociedade política que haviam estabelecido o estado liberal, na segunda metade do século XIX. As reações a esta concepção filosófica logo se intensificaram entre os intelectuais latino-americanos, constituindo-se o desenvolvimento de um argumento rigoroso contra o determinismo dos positivistas. Tratava-se não de uma luta pela existência propriamente dita, mas uma luta pela liberdade. Vivia-se uma crise de identidade.

Em contrapartida, alguns escritores de fins do século XIX propõem um modelo identitário para a América hispânica; no entanto, este seria construído tendo como base a Europa. A matriz teórica que Rodó lança mão para expressar este pensamento de origem europeia é evidenciada nas citações que faz de Ernest Renan, Jean-Marie Guyau, Auguste Comte, Thomas Carlyle, Hebert Spencer, entre outros. Seu eruditismo e apreço pelo que há de belo e bom, como assim expressava, o levaram a idealizar na juventude americana um status supremo.

Neste sentido, o literato privilegiou a ideia de que os gregos, mesmo em detrimento dos sul-americanos, representavam a boa conduta moral e 


\section{periferio}

espiritual e privilegia a afirmação destes serem os únicos sujeitos legítimos para a produção de conhecimentos e os únicos com capacidade de acesso à universalidade e à verdade, como fica evidente neste excerto de Ariel:

Compreendo muito bem que o exemplo dos fortes fornece inspirações, luzes, ensinamentos e não ignoro que uma atenção inteligente voltada para o exterior, a fim de recolher todas as partes a imagem do útil e do benéfico é singularmente fecunda quando se trata de povos que ainda estão se formando e modelando sua individualidade nacional (RODÓ, 1991, p. 70).

Contra a mísera condição dos povos que ainda estão se modelando, o uruguaio evoca uma Grécia que "fundou sua concepção de vida no concerto de todas as faculdades humanas". Na percepção do literato, a homogeneidade seria um limitador das singularidades, mesma que esta última tivesse como referência a cultura europeia.

Questões como a instabilidade política dos países; a dependência excessiva do capital estrangeiro, o que se dava em decorrência da importação de manufaturas e máquinas e exportação de matérias-primas; "faziam com que proliferassem conjeturas acerca da incapacidade do continente de incorporar a modernização e alcançar o progresso" (GOUVEIA, 2013, p. 06). Desta forma, muitos intelectuais latino-americanos, por conseguinte, não demoraram a apropriarem-se do discurso sociobiológico, uma vez que permitia validar cientificamente preconceitos raciais que já existiam desde a época colonial (MITRE, 2010, p. 214).

Não obstante, as formas de pensar, as metodologias e os paradigmas muitas vezes aprendidos nas universidades, que se debruçavam unicamente à estudar o conhecimento produzido pelos europeus e norte-americanos, acabavam por incutir uma perspectiva colonizada da realidade. Com isso, a construção de uma identidade nacional inferiorizada foi alimentada, assim como reforçou a compreensão de uma possível superioridade dos colonizadores. Nesta relação, as ciências sociais ajudaram a reforçar a ideia 


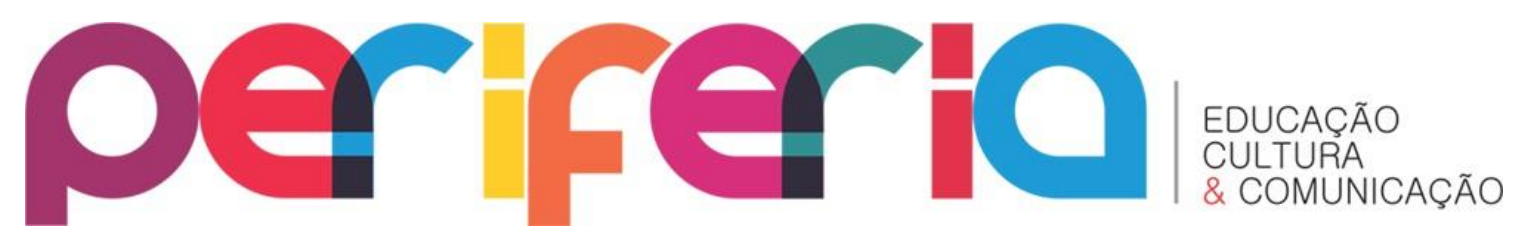

entre nós de que os colonizadores são Próspero, e nós, Caliban ${ }^{10}$, como bem observou Retamar ${ }^{11}$ (1980).

A esse respeito, Bonnici (2005, p. 302) pontua que o rigor crítico e analítico deve, portanto, caracterizar os estudos literários "sem o qual a sua paciente examinação de textos não faz sentido é o que penso estar na base para a imaginação e construção de um futuro que se deseje humano e livre". E considera que no presente o estado da teoria literária deve ser o de ruptura. A metáfora de Caliban é, assim, utilizada como exemplo de construção com forte fundo ideológico, quando faz referência ao "selvagem", ao "animal" com aspecto humano. Tal alegoria é justificada com base religiosa, legitimando-se, portanto, a comparação das aventuras marítimas e da "conquista dos povos ultramarinos" com as aventuras do povo hebraico.

Desta forma, observa-se que há um problema fundamental tanto para Rodó quanto para Retamar, que é narrar a construção da identidade da nação norte-americana para os sul-americanos. Há necessidade de estabelecer relação entre a modernidade na América Latina e o progresso na América, este comandado pelos Estados Unidos. Daí a insistente relação estabelecida entre "civilizado" e "bárbaro".

Para Rodó, o utilitarismo é um perigo que ameaça a nação latinoamericana, pois, na sua percepção, trata-se de uma influência sedutora, de barbárie disfarçada de civilização, em que o desenvolvimento material tornase fim em si mesmo e os valores espirituais são perdidos. 0 que está em jogo neste movimento civilizatório por meio da sedução são as identidades

\footnotetext{
10 o processo de criação da ideia de Caliban e de seus campos de força, do ponto de vista simbólico, corresponde de certa forma a uma projeção dos estereótipos e valores negativos a respeito dos negros e indígenas, justificados pelo cristianismo na época da invasão da América. Há uma evocação simbólica da relação estabelecida entre Próspero e Caliban que ajudam a definir a representação negativa de Caliban.

${ }^{11}$ Em 1974 Retamar escreveu "Caliban", um ensaio que é a interpretação contrária a Rodó de A Tempestade, a última obra de Shakespeare. Nesta peça Retamar retrabalha o simbolismo Ariel-Caliban. Caliban é um nativo escravizado por Próspero, o invasor; Ariel também é um nativo e um intelectual: ele tem que escolher entre se juntar Caliban ou servir a Próspero.
} 


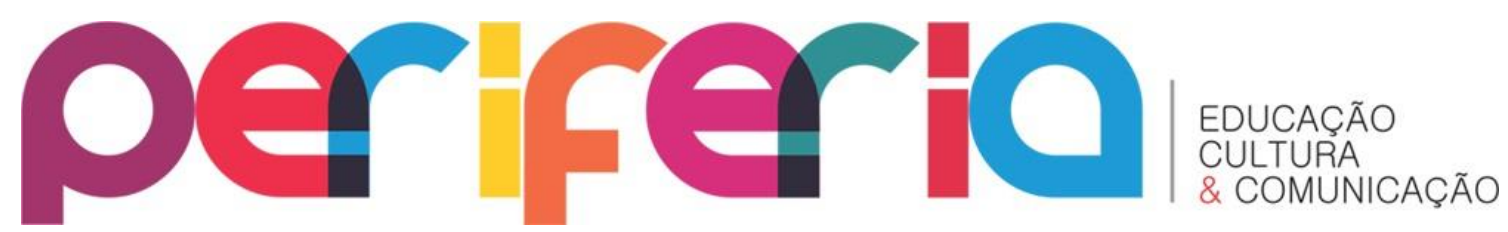

consideradas em trânsito dentro de deslocamentos estruturais da modernidade, conforme o escritor observa a seguir:

Se foi dito que o utilitarismo é o verbo do espírito Inglês, os Estados Unidos pode ser considerado a encarnação do verbo utilitário. E o Evangelho deste verbo é difundido em todos os lugares para os materiais milagres do triunfo [...] A poderosa federação colocará entre nós uma espécie de conquista moral. A admiração por sua grandeza e sua força é um sentimento que avança no espírito de nossos dirigentes, e talvez até mesmo na multidão, imprimindo fascinante vitória. [...] A tendência imitativa da nossa natureza moral, como disse Bagehot, tem a sua sede em que parte da alma está na credibilidade. 0 bom senso e a experiência vulgar seriam suficientes para estabelecer por si só esta relação simples. Imita-se aquele em cuja superioridade ou cujo prestígio é criado (RODÓ, 1991, p. 22, Tradução nossa).

O utilitarismo significa, portanto, para o escritor, influência negativa, em detrimento dos valores verdadeiramente civilizadores e esteticistas, por ele vislumbrados na cultura clássica europeia. Mas o que está em questão, entretanto, para ele, é a disputa entre a democracia utilitária (representada por Caliban) e os valores verdadeiramente espirituais. Ariel é o espírito, a nova filosofia latino-americana; e Caliban é a tecnologia, a racionalidade instrumental, a materialidade do positivismo filosófico anglo-saxão. E o principal argumento de Rodó contra a imitação do caminho dos Estados Unidos é que ele leva à mediocridade.

O escritor uruguaio é influenciado por metáforas, como num jogo de símbolos: Ariel é o símbolo do "espiritual", de uma cultura elitizada que abandona o mundo para se tornar um espírito do universo; Próspero, à mercê do Caliban, representa uma falsa maneira de conduzir o povo a partir das massas populares, em razão de interesses capitalistas. Ariel é o principal foco simbólico, pois representa um tipo específico de reação ao poder, em que o subordinado, embora com relutância, age de acordo com os comandos dos mestres e aguarda pacientemente por sua liberdade. 


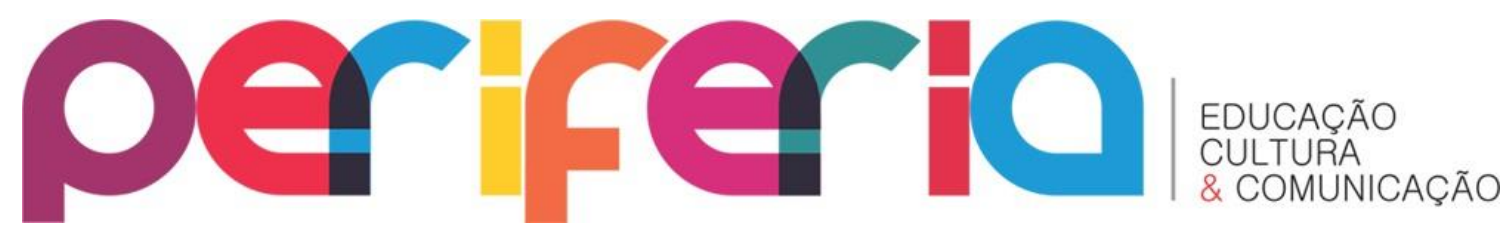

A colonialidade do poder, portanto, empreendida aqui pela sedução, a qual também é uma de suas manifestações, para Quijano (2009, p. 101), perpassa pelos eixos do trabalho, de raça e de gênero, numa estrutura comum de poder. No processo histórico de ocidentalização da América Latina, Caliban, além de representar a figura do Outro, também é símbolo da rebeldia contra o colonialismo norte-americano, haja vista que este continente sul já se encontra impregnado pelos valores etnocêntricos, impostos a ele desde a sua "descoberta".

\section{A EDUCAÇÃO LATINO-AMERICANA ESPIRITUALIZADA EM “ARIEL”}

$\mathrm{Na}$ transição entre os séculos XIX e XX, as relações interamericanas chegaram ao máximo de tensão. Os governos hispano-americanos, em geral, reagiam com suspeita e desconfiança em relação a esse novo interesse dos Estados Unidos no hemisfério. Neste momento de crise, Rodó pensa a situação social da América Latina, com destaque aqui para seu pensamento sobre educação, frente ao imperialismo norte-americano.

Para os teóricos e intelectuais europeus, a pretensa homogeneidade dos povos latino-americanos "residia no fato cientificamente inconteste de que todos estavam condenados ao atraso, não thes restando outro caminho que o da submissão passiva aos povos superiores" (AGUIAR, 2000, p. 305). Contrárias às ideias de Rodó, diversas críticas também eram formuladas por intelectuais tendo como base os fundamentos das teorias sociais europeias, como o Darwinismo social, o evolucionismo e o positivismo, tríade teórica fundamental onde se alicerça, de certo modo, o auge da modernidade ocidental.

Para muitos intelectuais brasileiros, como Renato Ortiz (1994) e Manoel Bomfim (2005), a forma contrária de pensar sem referências à essas correntes teóricas era considerada marginal e vista como dissidente naquela época (AGUIAR, 2000), pois eram tais fundamentos teóricos que sustentavam o pensamento social europeu e que forjaram a base do racismo científico, 


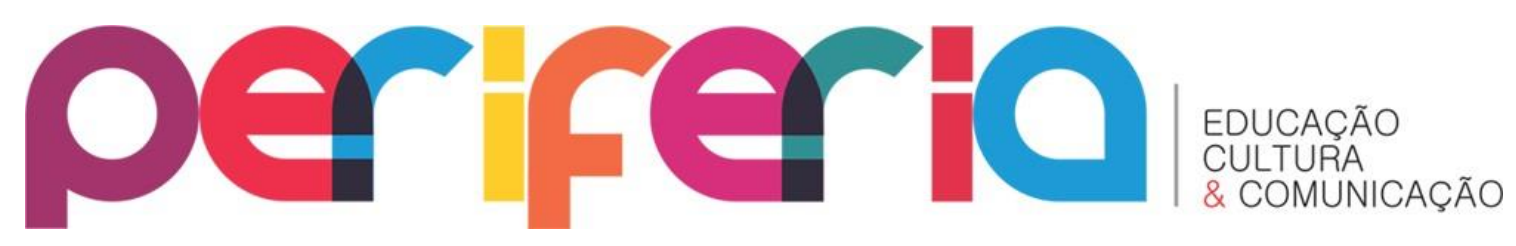

tipificando essa forma de pensar como expressão de um discurso dominante que apenas visava legitimar interesses colonialistas europeus na América Latina.

Esse conflito teórico e existencial levou Rodó apensar a sociedade latino-americana de forma mais crítica a partir da relação entre educação, sociedade e espiritualidade. Tal perspectiva é exemplificada em Ariel onde ele discorre sobre uma educação inserida em um contexto de decadência social, na interação com as incontáveis faces do capitalismo norte-americano que precisa mudar, ou melhor, evoluir a partir de uma educação espiritualizada. Para tanto, "a juventude, que assim significa luz, amor e energia na alma dos indivíduos e das gerações, também existe com o mesmo significado no processo evolutivo das sociedades" (RODÓ, 1991, p. 18).

No contexto social latino-americano, déficit de determinados tipos de conhecimentos, na visão de alguns intelectuais mais resistentes, estava relacionado, além da sedução pela implantação do modelo norte-americano de desenvolvimento, à uma democracia mal entendida, haja vista que na concepção de Rodó não havia distinção que confundisse ou anulasse mais facilmente o espírito do povo do que a que "ensina que a igualdade democrática pode significar uma igual possibilidade, mas nunca uma igual realidade, de influência e prestígio entre todos os membros de uma sociedade organizada." (Ibid., p. 62-63).

Nesse sentido, ele defendia que "sendo a democracia um evento inevitável, Ariel deveria ser o símbolo da democracia, a busca por interesses ideais". Ariel é, portanto, um objetivo alcançável. Figura espiritual, capaz de ir além dos interesses pragmáticos, o que só seria possível com o enfrentamento das influências externas utilitaristas. Somente assim seria possível a reconstituição da ideia de igualdade, mascarada sob o falso argumento da democracia. A democracia, a exemplo disto, "não deveria ser um jogo de número para o apaziguamento das massas, nem usada para a busca de bem material" (RODÓ, 1991). 


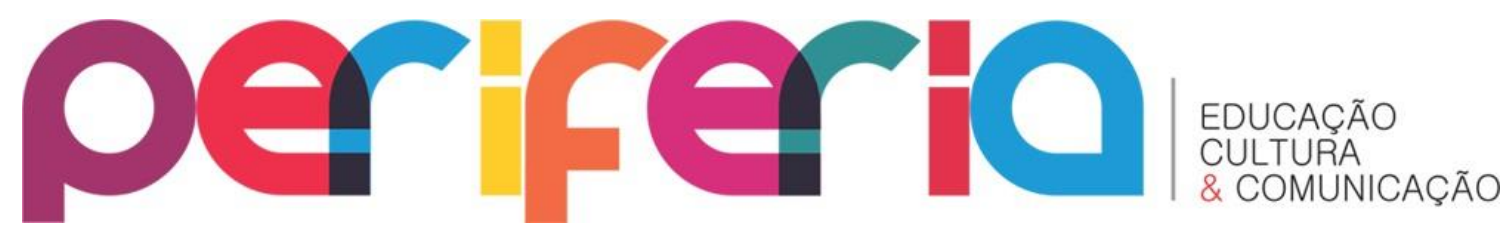

Fica, portanto, evidente seu entendimento de que a distribuição cultural, o controle da capacidade econômica e política estão sob os domínios daqueles que também possuem, pelo poder, o controle do conhecimento. Estas são as premissas que o permitem também compreender que o controle das instituições culturais, e do conhecimento, consentem o aumento do poder e do controle de uma classe sobre a outra, pois, para ele,

\begin{abstract}
A influência política de uma plutocracia representada pelos todo-poderosos aliados dos trustes, monopolizadores da produção e donos da vida econômica [...] traz à lembrança, de maneira muito provavelmente oportuna, o surgimento da classe enriquecida e soberba que, nos últimos tempos da república romana, foi um dos antecedentes visíveis da ruína da liberdade e da tirania dos Césares. E a preocupação exclusiva com o engrandecimento material - nume daquela civilização - impõe assim a lógica de seus resultados na vida política, bem como em todas as ordens de atividade, conferindo o primeiro lugar ao struggle-for-life ousado e astuto, convertido pela brutal eficácia de seu esforço na suprema personificação da energia nacional. (Ibid., p. 88).
\end{abstract}

A visão de Rodó era de enaltecera cultura latino-americana e denunciar o que a ameaçava, por isso ele a identificava com Ariel, já que o modelo de saber e desenvolvimento propostos pautavam-se num sistema político cujo poder era exercido pelo grupo mais rico.

Portanto, o escritor uruguaio entende que seria necessário capacidade crítica e afirmação intelectual diante da distribuição da cultura no mundo moderno, quando relacionada à presença ou à ausência de poder em determinados grupos sociais. Neste sentido, o intelectual também advoga 0 papel do Estado no desenvolvimento da cultura moral e no conhecimento, como uma instituição de poder, pois, para ele, o verdadeiro, o digno conceito de igualdade repousa na ideia de que "todos os seres racionais são dotados por natureza de faculdades capazes de um desenvolvimento nobre. 0 dever do Estado consiste em colocar todos os membros da sociedade em condições eqüitativas de buscar seu aperfeiçoamento" (RODÓ, 1991, p. 62-63). 


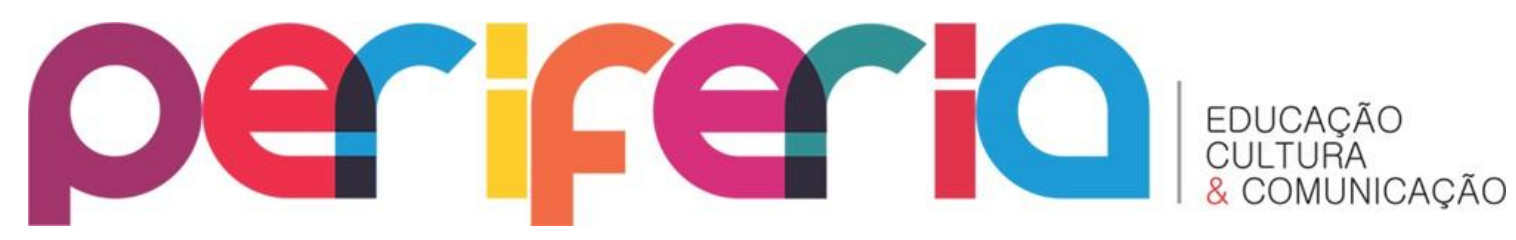

Quando Rodó critica o utilitarismo norte-americano, ou quando alude ao papel das metrópoles na civilização moderna, tem como referência a entrada de uma grande quantidade de imigrantes no Uruguai e a fraca composição das elites locais, as quais eram, para ele, incapazes de orientar o enorme contingente humano que estava chegando. Pois entende que " $O$ acelerado crescimento de nossas democracias, com o incessante acréscimo de uma enorme multidão cosmopolita e o afluxo imigratório, que se incorpora a um núcleo ainda frágil [...] expõe-nos no futuro aos perigos da degeneração democrática." (MATHIAS; VALES, 2010, p. 54-55).

Portanto, a ideia de democracia está presente de forma constante em Ariel e é utilizada como contraponto para combater o avanço das políticas neoliberais, com as quais se têm investido para redefinir a democracia nos termos do livre-mercado. Daí a utilização deste princípio em função de atender aos "consumidores" e aos produtos, inclusive educacionais, que passarão a circular nos mercados, de acordo com os "interesses pessoais", o que exaspera a concorrência e o individualismo.

Este é o ponto fundamental da crítica de Rodó, pois há evidente tentativa de se atender aos prazeres imediatos, utilitaristas, em detrimento das questões de cunho espiritual, haja vista que, para o escritor, "Os livres são considerados os que têm 'domínio de si', mas só têm esse domínio os que aderem aos ensinamentos de Próspero, que se dedicam ao ócio, ao pensamento abstrato e ao culto ao belo" (RODÓ, 1991, p. 35-39). É a partir de tal concepção espiritualizada de educação que, mesmo que o literato faça duras críticas à cultura norte-americana, ainda sustenta expectativas de que os norte-americanos um dia alcancem "inteligência, sentimento e idealidade", que thes possibilitem serem respeitados como "exemplo humano, generoso, harmonioso e seleto" (Ibid., p. 218).

Rodó combate o menosprezo por parte dos Estados Unidos à tradição europeia e critica a arrogância norte-americana por desconsiderar a tradição civilizatória da Europa. Para ele seria quase que impossível criar um mundo novo desvinculado do passado, de maneira a estabelecer uma ordem burguesa 


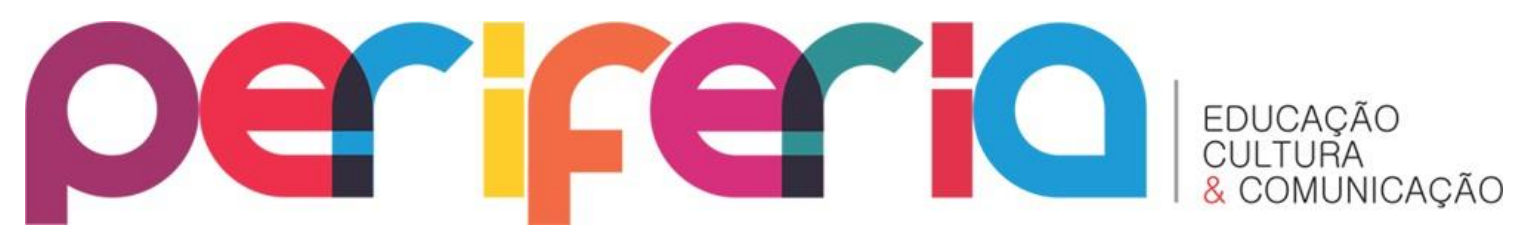

em que não haveria espaço para o que chamou de "sabedoria superior" (Ibid., p. 85). Assim, entende que não caberia, sob qualquer hipótese, a concepção utilitária de "igualdade na mediocridade" (Ibid., p. 76).

O avanço do imperialismo norte-americano, para o literato, representava a razão de grande número de indivíduos de uma sociedade, neste caso a América Latina, terem perdido interesse pela democracia ou por qualquer preocupação ideal. Mesmo assim ele acreditava que no futuro existiria "o idealismo, a abstração, a vitória de Ariel sob o comando de Próspero" (Ibid., p. 78). O humanismo e o idealismo latinos eram exaltados por Rodó em detrimento do utilitarismo e do materialismo anglo-saxão.

A importação dos padrões estadunidenses representa para Rodó uma ameaça à originalidade insubstituível dos povos, pois, o intelectual não via “[...] glória no propósito de desnaturalizar o caráter dos povos - seu gênio pessoal - para lhes impor a identificação com um modelo estranho a que sacrifiquem a insubstituível originalidade de seu espírito" (RODÓ, 1991, p. 71).

Do ponto de vista da democracia, Rodó quer demonstrar a importância da educação na definição de um povo, de sua cultura e de sua política, afirmando uma cultura latino-americana valorosa, altruísta, construída no ócio e na abstração, e oposta ao utilitarismo frio, egoísta e atomizado estadunidense. Para tanto, e como critério básico, segundo ele, precisamos cuidar da independência interior, da personalidade, como uma forma de respeito próprio (lbid., p. 23).

Nesse sentido, chama a atenção para a juventude, uma vez que esta, para ele, é imprescindível no processo de desenvolvimento social, pois a juventude traz consigo entusiasmo e esperança, o que corresponde à "luz, amor e energia na alma dos indivíduos e das gerações, também existe com 0 mesmo significado no processo evolutivo das sociedades" (Ibid., p. 18). Pois "Nenhum sinal de educação e inteligência pode basear-se no isolamento ou ingênua ignorância deliberada." (Ibid., p. 05). 


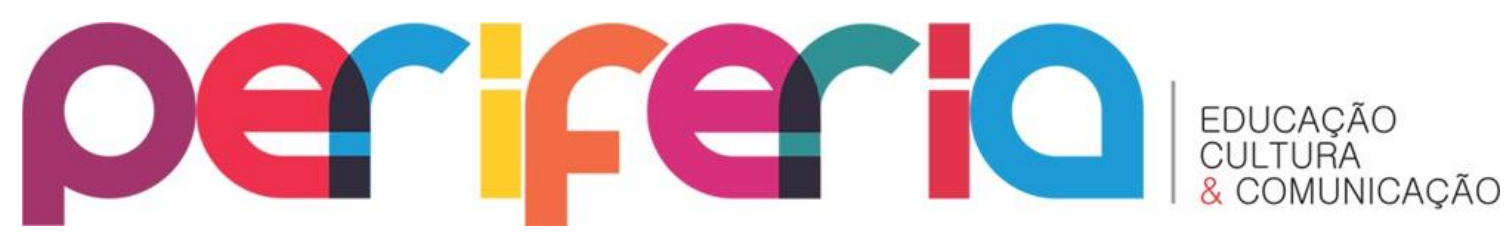

O escritor chama atenção aqui para a problemática do conhecimento dito oficial, às políticas do senso comum, com a regulação desse mesmo conhecimento pelos interesses econômicos e como políticas culturais. Esta posição crítica perante as políticas neoliberais o inquietavam sobremaneira. Para ele, tais questões sinalizam para a provável destruição dos saberes culturais dos povos, dos conhecimentos historicamente constituídos, assim como para seus múltiplos efeitos do poder. Ao relacionar Ariel ao símbolo da igualdade democrática, a educação e a democracia não deveriam ser um jogo de número para o apaziguamento das massas, nem estimulada para o fim da busca de bem material, mas deveria ser o símbolo da democracia, a busca por interesses ideais (RODÓ, 1991).

Em linhas gerias, podemos dizer a concepção de educação de Rodó é fundamentada na contradição de categorias que o ajudaram pensar e realidade latino-americana. Espiritualidade, idealismo, racionalismo, progresso, materialismo e escravidão andam juntos e moldam as relações de produção no mundo moderno, portanto, precisam ser questionados. Caberia, portanto, uma educação espiritualizada e a desconstrução de todas as formas de imposições materialistas, o que se dá pelo exercício crítico da cidadania, fundamentados nas ideias de democracia e igualdade. Somente desta forma, para ele, seria possível libertar-nos da tirania, dos costumes e dos hábitos que vislumbram o materialismo.

\section{CONSIDERAÇÕES FINAIS}

Neste texto ficou evidente que a crítica ao utilitarismo e ao materialismo dos Estados Unidos foi tema corrente, na virada do século XIX para o XX, entre os intelectuais latino-americanos que denunciavam a influência crescente deste país nas questões do continente. Observamos que Rodó viveu nesse cenário intelectual e se destacou com suas críticas contundentes aos Estados Unidos, em seu ensaio Ariel, cuja preocupação 


\section{periferio}

maior era a influência moral que este país poderia exercer sobre os povos da América Latina.

O literato defende o saber não como algo dado, com fins utilitários, mas sim enquanto uma realidade que deve ser criticamente examinada e combatida, cuja proposta rompia com a concepção até então dominante da educação. Em Ariel, ele situa exemplarmente esta sua visão de educação inserida em um contexto de decadência social, na interação com as incontáveis faces do capitalismo norte-americano.

Como contraponto, ele propõe o desenvolvimento de uma consciência crítica, porque sem ela entende que nos tornaremos meros depositários de informação. Quando da atribuição dos valores do mercado à educação, presume que o indivíduo passe a se transformarem produto, tendo em vista que assim ele se desumanizaria, ao tempo em que estaria em constante processo de alienação histórica, preconizado pelo atual sistema pedagógico materialista.

$\mathrm{Na}$ concepção de Rodó, a educação sob a perspectiva utilitarista, aquela do "aprender a aprender", apresenta-se como um instrumento de reprodução da própria alienação. Há, para o escritor uruguaio, uma tentativa de apartar o indivíduo da história social, ou seja, da percepção do conhecimento socialmente construído e acumulado. Prepara-se, assim, com esta ideia, os indivíduos para se alienarem no próprio processo do conhecimento. Ao invés de preparar indivíduos para se perceberem e se verem nos processos, essa pedagogia os cega, os torna indiferentes à própria condição, e os ajuda a produzir a própria tragédia.

Com Ariel, Rodó trava uma luta de resistência e bloqueio às políticas que tentam construir e manter os Estados Unidos como alternativa e um bloco hegemônico dominante nas Américas. Trata-se de um texto que possui como base o pensamento europeu e imprime este pensamento na ressignificação e na reconstituição identitária dos povos latino-americanos, podendo assim ser caracterizado como uma estratégia pós-colonial de revide e de resistência aos 


\section{periferio}

efeitos do colonialismo nas Américas, na passagem do século XIX para o século $X X$.

O escritor pensa a educação a partir de sua função social, a qual ele atribui valor extremo, na medida em que esta logre preparar o indivíduo para o exercício da ética e da cidadania, o que supõe, ainda, educá-lo para compreender e ter acesso a todas as manifestações da cultura humana espiritualmente referendadas, mesmo em oposição ao ângulo puramente pragmático, cuja qualidade se resume a compreender o indivíduo como produtor-consumidor na dinâmica do mercado.

Como um clássico da literatura sul-americana, Ariel possui um papel que foi e continua a ser decisivo, o de ajudar pensar a educação para além do modelo europeu sugerido por Rodó, mas como elemento fundamental e indispensável no enfrentamento ao utilitarismo, considerando ainda os campos da cultura, da cidadania, da moral e da ética, os quais ajudariam na composição do que ele chamava de independência interior espiritualizada, como uma marca forte de personalidade de um povo.

\section{REFERÊNCIAS}

AGUIAR, R. C. O rebelde esquecido.Tempo, vida e obra de Manoel Bomfim. Rio de Janeiro: Topbooks, 2000.

ANDO, M. Y.; BONNICI, T. Entre a dominação e o revide: a resposta do Colonizado. Em Apenas Um Curumim De Werner Zotz. Publ. UEPG Ci. Hum.,Ci. Soc. Apl., Ling., Letras e Artes, Ponta Grossa, 13 (2) 19-32, dez. 2005.

BONNICI, T. O pós-colonialismo e a literatura: estratégias de leitura. Maringá: Eduem, 2000.

Introdução ao estudo das literaturas pós-coloniais. Mimesis, Bauru, v. 19, n. 1, p. 07-23, 1998.

BOMFIM, M. A América Latina: males de origem. Rio de Janeiro, Topbooks Editora, 2005. 


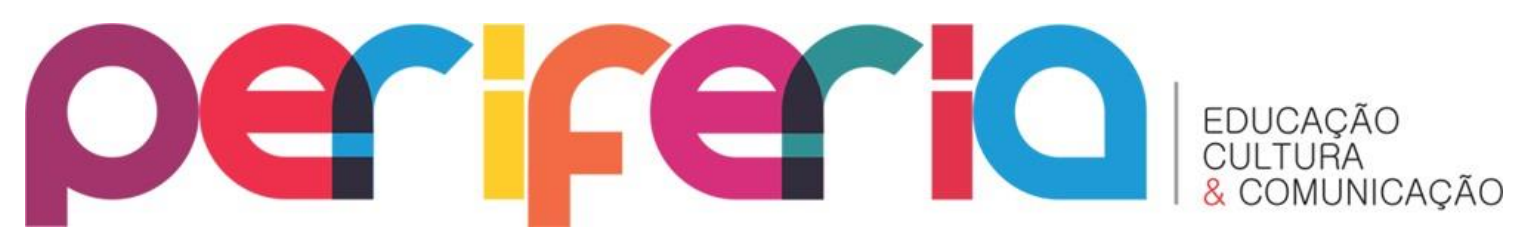

DUSSEL, H.1942: O encobrimento do outro: a origem do mito da modernidade. Conferências de Frankfurt. Rio de Janeiro: Vozes, 1995.

GOUVEIA, R. Rodó e o pensamento político latino-americano na virada do século XX. XXVII Simpósio Nacional de História. Conhecimento Histórico e Diálogo Social. Natal, RS, 2013.

MARTÍ, J. Mãe América: nossa América. In: RETAMAR, Roberto Fernández (org.) José Martí, Nossa América (antologia). Tradução de Maria Angélica de Almeida Trajber. São Paulo: Editora Hucitec, 1983.

MATHIAS, S. K.; VALES, T. P. O militarismo não

Uruguai. História [online]. 2010, vol.29, n.2, pp. 50-70.

MARIÁTEGUI, José Carlos. Sete ensaios de interpretação da realidade peruana. São Paulo: Editora Expressão Popular, 2008.

MARICHAL, J. De Martí a Rodó: el idealismo democrático (1870-1910). Cuatro fases de lahistoria intelectual latinoamericana. Cáteo, 1978.

MITRE, A. Estado, Nação e Território na Bolívia Oligárquica, 1850-1914. In:PAMPLONA, M. A.; MÄDER, M.E. (org.). Revoluções de independências e nacionalismos nas Américas: Peru e Bolívia. São Paulo: Paz e Terra, 2010. pp. 193-237.

- Fenômenos de massa na sociedade oligárquica - o despontar da modernidade em Ariel de Rodó. In: MITRE, Antonio. O dilema do centauro Ensaios de teoria da história e pensamento latino-americano. UFMG, 2003.

QUIJANO, A. Colonialidade do poder e classificação social. In SANTOS, Boaventura de Sousa; MENESES, Maria Paula (orgs.). Epistemologias do Sul. Coimbra: Edições Almedina, p. 73-117, 2009.

RAMA, A. A Cidade das Letras. Trad. Emir Sader. São Paulo: Brasiliense, 1985.

RETAMAR, R. F. “Caliban”, Revolucion. Letras, Arte, Editorial Letras Cubanas: Havana, 1980. pp.221-276.

ORTIZ, R. Memória coletiva e sincretismo científico: as teorias raciais do século

XIX. In: Cultura brasileira e identidade nacional. São Paulo: Brasiliense, 1994.

RODÓ, J. E. Ariel. Campinas, SP: Editora da Unicamp, 1991.

Ariel. 1900. In: VACCARO, A. J. Obras Completas de José Enrique

Rodó. Buenos Aires: Antônio Zamora, 1967. pp. 162-210. 


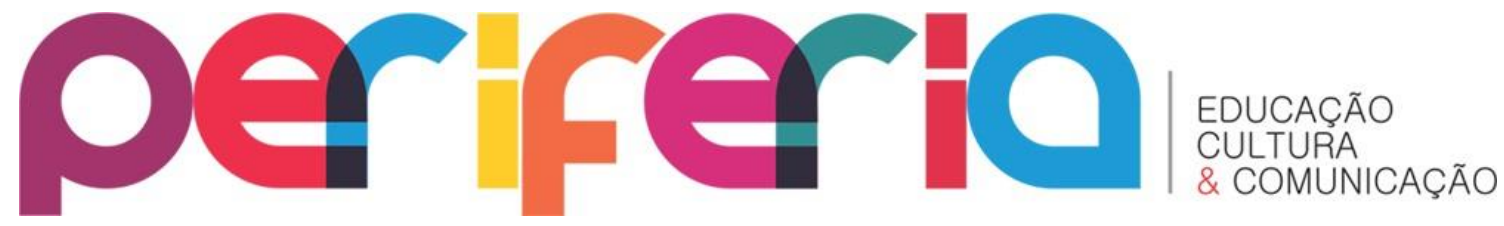

SANTOS, B. de S. Entre Próspero e Caliban: colonialismo, pós-colonialismo e inter-identidade. In: RAMALHO, M.I.; RIBEIRO, A. S. (orgs.). Entre ser e estar: raízes, percursos e discursos da identidade. Porto: Afrontamento, 2001.

TURATTI, R. A. José Enrique Rodó, a “Geração Hispano-Americana de 98” e o projeto para uma identidade americana. Revista Eletrônica da ANPHLAC, n.13, p. 227-250, jul./dez. 2012. 